\title{
A COMPARISON OF THE STRESS ANALYSIS OF AN UNRESTORED AND RESTORED TOOTH WITH AMALGAM AND COMPOSITE RESIN
}

\author{
Halil Aykul* and Mustafa Toparli* ${ }^{*}$ \\ *Department of Mechanical Engineering, Çorum Faculty of Engineering, Gazi \\ University, Çorum-TURKEY \\ **Department of Metallurgical and Materials Engineering, Faculty of Engineering, \\ Dokuz Eylül University, Bornova, İzmir-TURKEY
}

\begin{abstract}
Finite element models were developed for an unrestored tooth and restored tooth. The tooth was considered to be in a restored state with amalgam and composite resin on glass-ionomer as the base material. For this study, an axisymmetric model of a maxillary second premolar that included an alveolar bone was used. A load of $200 \mathrm{~N}$ at an angle of $45^{\circ}$ to the radial axis was applied on the occlusal margin of the tooth. The tooth was assumed isotropic, homogenous and elastic. The authors using FORTRAN 77 prepared all calculation programs. The distributions of radial axial and shear stresses were plotted with length of radial for some critical points.
\end{abstract}

Keywords- Restorative materials, amalgam, composite resin, finite element, stress analysis.

\section{INTRODUCTION}

There is an increasing demand for dental restorations that match tooth tissue and bond to tissue effectively, thereby allowing conservative cavity preparation. This demand is strongly influenced by aesthetic consideration and by the desirability of avoiding the use of amalgam. The failure of dental restorations through recurring caries, marginal discrepancies, and tooth fracture are topics of substantial clinical significance.

Several studies have been searched restored tooth and unrestored tooth. Gher et al. [1] reported clinical survey of 100 fractured teeth, 92 cases involved teeth that had been previously restored. Furthermore, from a clinical examination of 206 fractured posterior teeth, Eakle et al. [2] found that over 93\% were restored with amalgam, $82 \%$ of which were restored with composite resin. Using destructive methods, some researcher investigated composite and amalgam restorations [3-5].

Although many attempts have been carried out to improve dental restorative materials, there are still big differences, particularly in the mechanical and physical properties of tooth and restorative materials. To understand the mechanisms responsible of tooth fracture, the stress distribution within restored and unrestored teeth that results from mastication force has been studied extensively. Several studies have used finite element techniques in attempts to gain understanding of the process of stress dissipation in teeth. Finite element stress analysis is a form of mathematical modelling which examines the deformations under the load of a model composed of a mesh of elements with given mechanical properties. Toparli et al. [6] investigated the distribution of stresses restored tooth from the mastication force using three-dimensional finite element method. Arola et al. [7] identified differences in the mechanical behaviour of unrestored molar with that of a molar with class II amalgam or composite mesial occlusal distal (MOD) restoration with dentin and enamel bonding. Three individual finite element 
models were developed including an anatomical crown model. Also, a developed automesh program was used to generate 30 three-dimensional finite element models simulating the biomechanics for multiple factorial design of the MOD gold restoration in a maxillary second premolar [8]. The results showed that enlarging the volume of the MOD cavity significantly increased stress in enamel but did not intentionally stresses in dentin.

The aim of this study was to calculate the stress distribution in dentin of an unrestored and restored with amalgam and composite resin using the axisymmetric finite element method.

\section{MATERIALS AND METHODS}

Axisymmetric finite element model of the maxillary second premolar tooth that included alveolar bone was investigated for analysis of the stress distribution (Fig.1). The geometry of the tooth was taken from the textbook by Ash [9]. This finite element model was completed from elements having 8 nodes (hexahedral element). The total number of elements was 485 with 526 nodes. All the materials and vital tissues were presumed elastic, homogenous and isotropic, which included continual interfaces between materials.

In this study amalgam, composite P50 and glass-ionomer were studied (Table 1). Three models were evaluated that unrestored, restored with amalgam and restored with composite resin on a base made of glass-ionomer material. The diameter and height of the glass-ionomer and restorative material were $4.3 \mathrm{~mm} \times 0.53 \mathrm{~mm}$ and $4.3 \mathrm{~mm} \times 4.67$ $\mathrm{mm}$, respectively. The mechanical properties of materials and tooth were determined according to literature survey $[6,10$ and given in Table 2 .

Table 1 Restorative materials

\begin{tabular}{ll}
\hline Material & Manufacturer \\
\hline Amalgam & De Trey Dentsply, Weybridge, U.K. \\
Composite P 50 & 3M, St Paul, MN, USA \\
Glass-ionomer & Cavex Avalloy, Hoorlem, Netherlands \\
\hline
\end{tabular}

Table 2 Mechanical properties of restorative materials and tooth

\begin{tabular}{cccc}
\hline Material & $\begin{array}{c}\text { Modulus of elasticity } \\
(\mathrm{MPa})\end{array}$ & Poisson's ratio & $\begin{array}{c}\text { Tensile strength } \\
(\mathrm{MPa})\end{array}$ \\
\hline Amalgam & 13720 & 0,33 & $48-69$ \\
Composite P 50 & 3963 & 0,30 & $41-69$ \\
Glass-ionomer & 12162 & 0,30 & 5.5 \\
Dentin & 18600 & 0.31 & 48 \\
Enamel & 41400 & 0,30 & 10 \\
Pulp & 0.003 & 0.45 & - \\
Alveolar bone & 13800 & 0,26 & 121
\end{tabular}




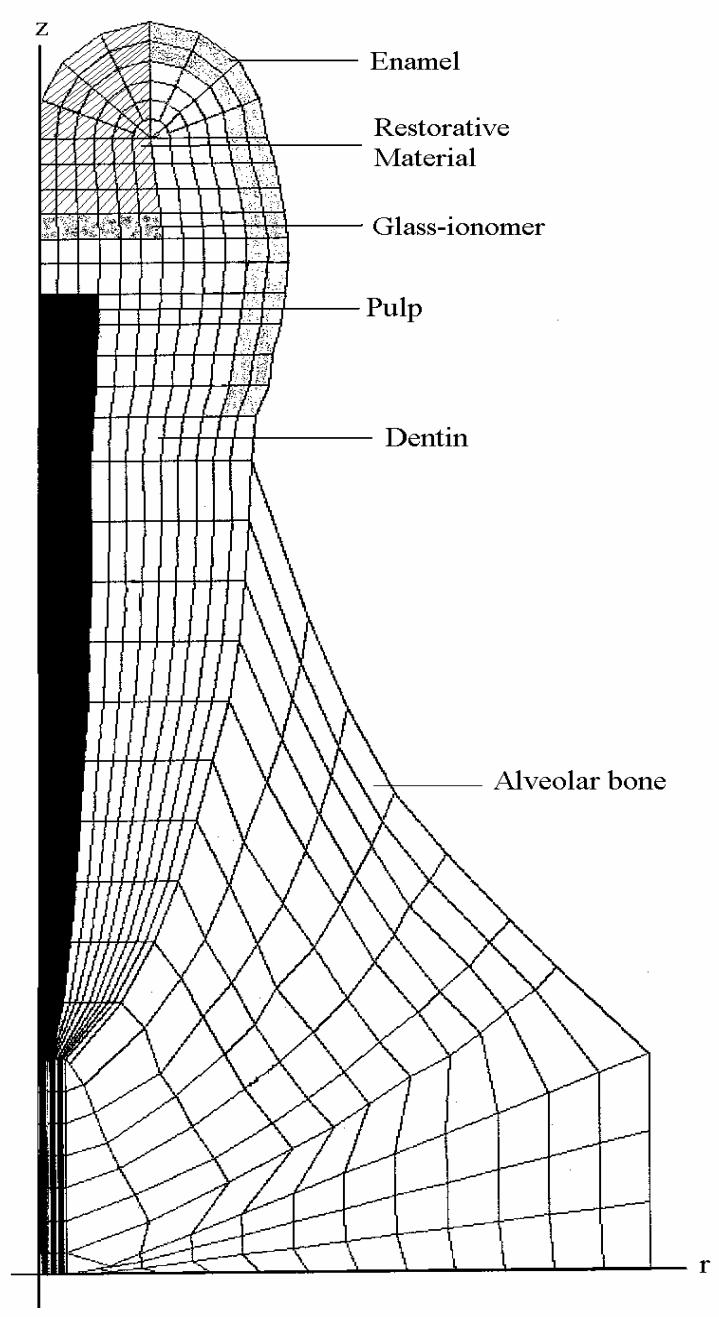

Fig. 1 The axisymmetric finite element model of tooth

A total external load of $200 \mathrm{~N}$ was applied to the occlusal margin of the tooth (Fig. $2)$. The angle between the line of the force and the radial axis was selected to be $45^{\circ}$. Radial ( $\mathrm{r}$ direction) and axial ( $\mathrm{z}$ direction) stress and shear (rz direction) stress values were calculated and plotted at three radial sections that glass-ionomer-dentin interface, glass-ionomer-restorative material interface and restorative materials. 


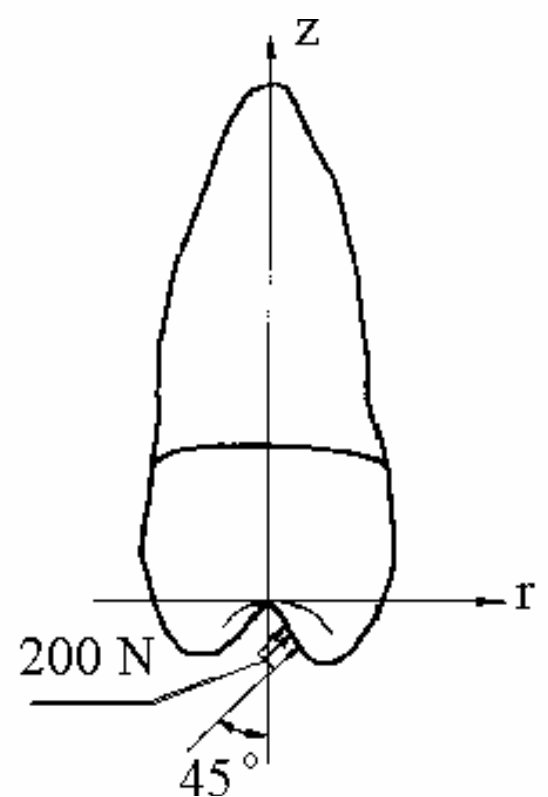

Fig. 2 Applied forces on the tooth

\section{RESULTS}

Figs 3-5 show stress distributions as radial, axial and shear stresses on the glass inomer-dentin interface. The minimum radial stress values occur on the unrestored tooth as seen in Fig. 3. The peak radial tensile and compressive stresses take place with amalgam as a restorative material. The maximum tensile and compressive stresses become 13.6 $\mathrm{MPa}$ and 14.5 $\mathrm{MPa}$, respectively. The axial stress values show the same tendency as seen in Fig. 4. The largest compressive stress occurs on the centre of tooth when amalgam has been used. Fig. 5 shows the distribution shear stress on the glass inomer-dentin interface. The shear stress values increase using amalgam restorations. When composite resin is used instead of amalgam, all stresses are relatively smaller.

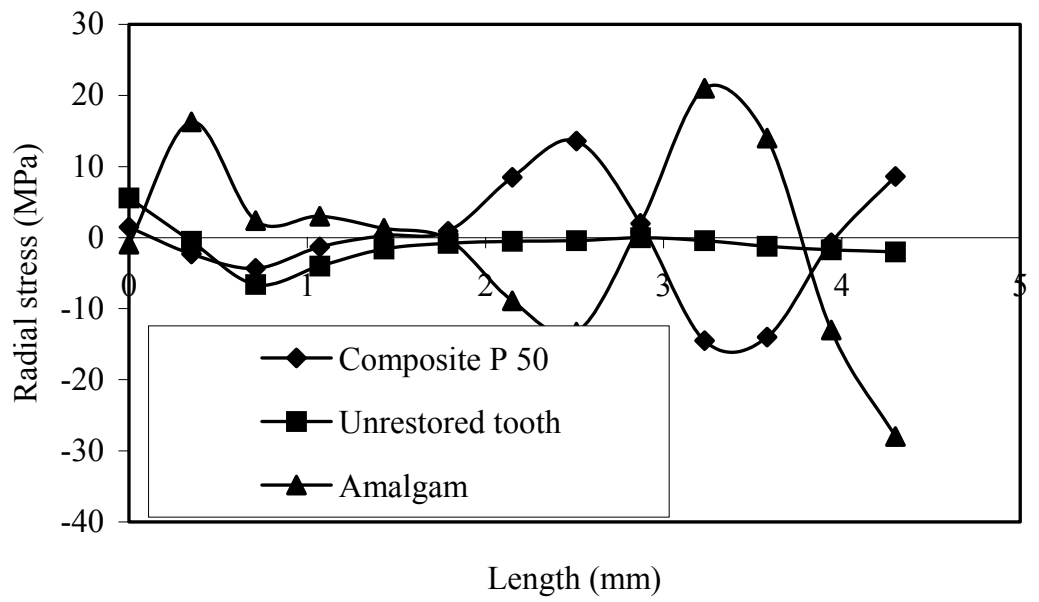

Fig. 3 The radial stress on glass inomer-dentin interface 


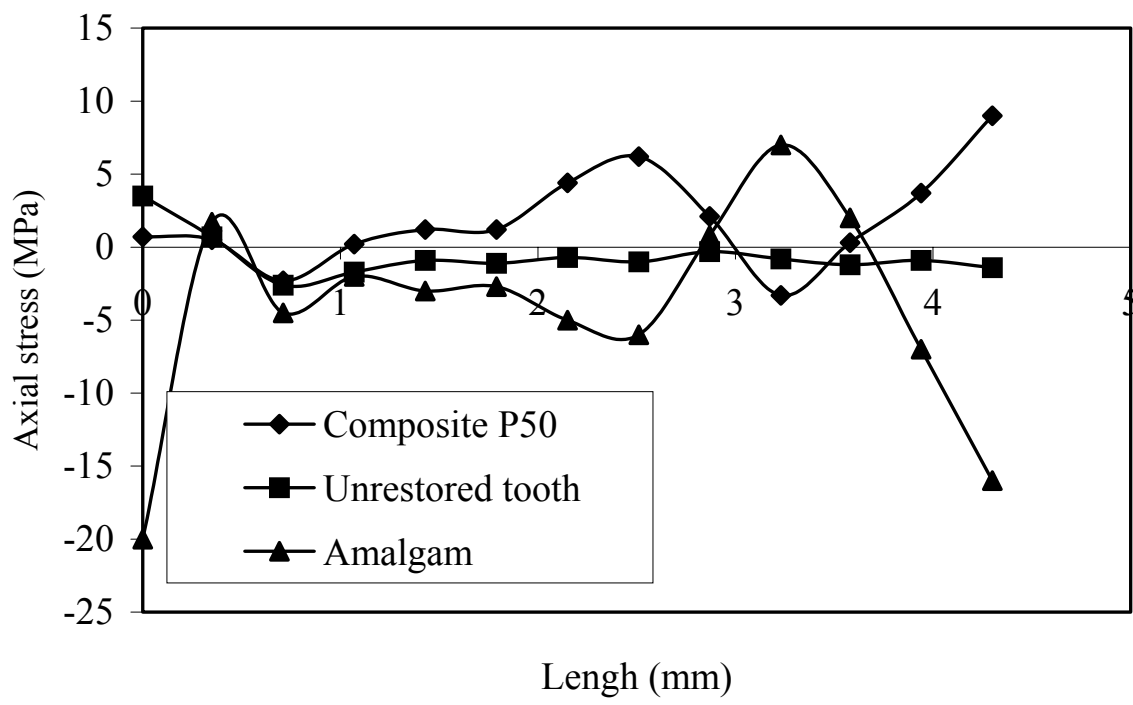

Fig. 4 The axial stress on glass inomer-dentin interface

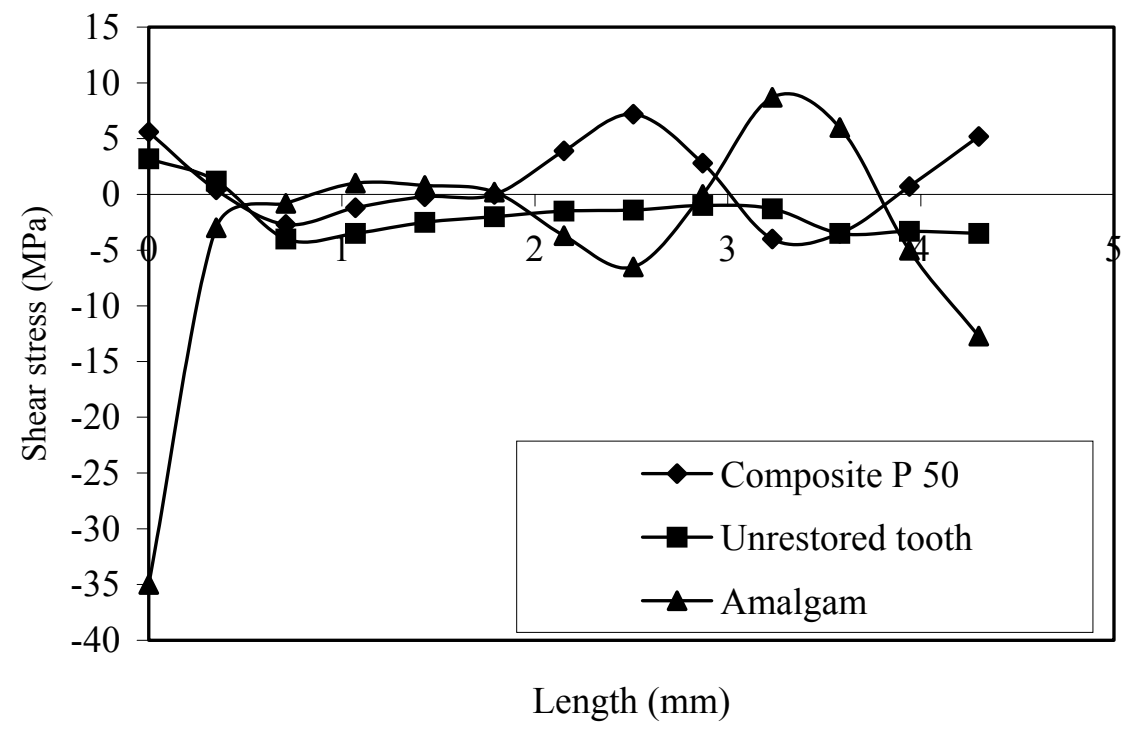

Fig. 5 The shear stress on glass inomer-dentin interface

In Fig.6, the stress in the radial direction on the glass inomer-restorative material interface is shown. It is clear that the maximum tensile stress value reached is $9 \mathrm{MPa}$. The largest stress values occur when composite P50 has been used as restorations. On the contrary, the smallest values take place in the case of unrestored tooth. Fig. 7 illustrates axial stress distribution on the same place. These stress values is smaller than radial stress. Also, when amalgam has been used, the maximum tensile and compressive stress values occur on the glass ionomer-restorative material interface. The maximum 
tensile and compressive stresses become $10 \mathrm{MPa}$ and $14 \mathrm{MPa}$, respectively. The shear stress distribution in the radial direction on the interface is given in Fig. 8. As seen in figure, the tensile and compressive stress values change with length. In the centre of tooth, maximum compressive stress occurs and the stress value is $8 \mathrm{MPa}$ when amalgam has been used.

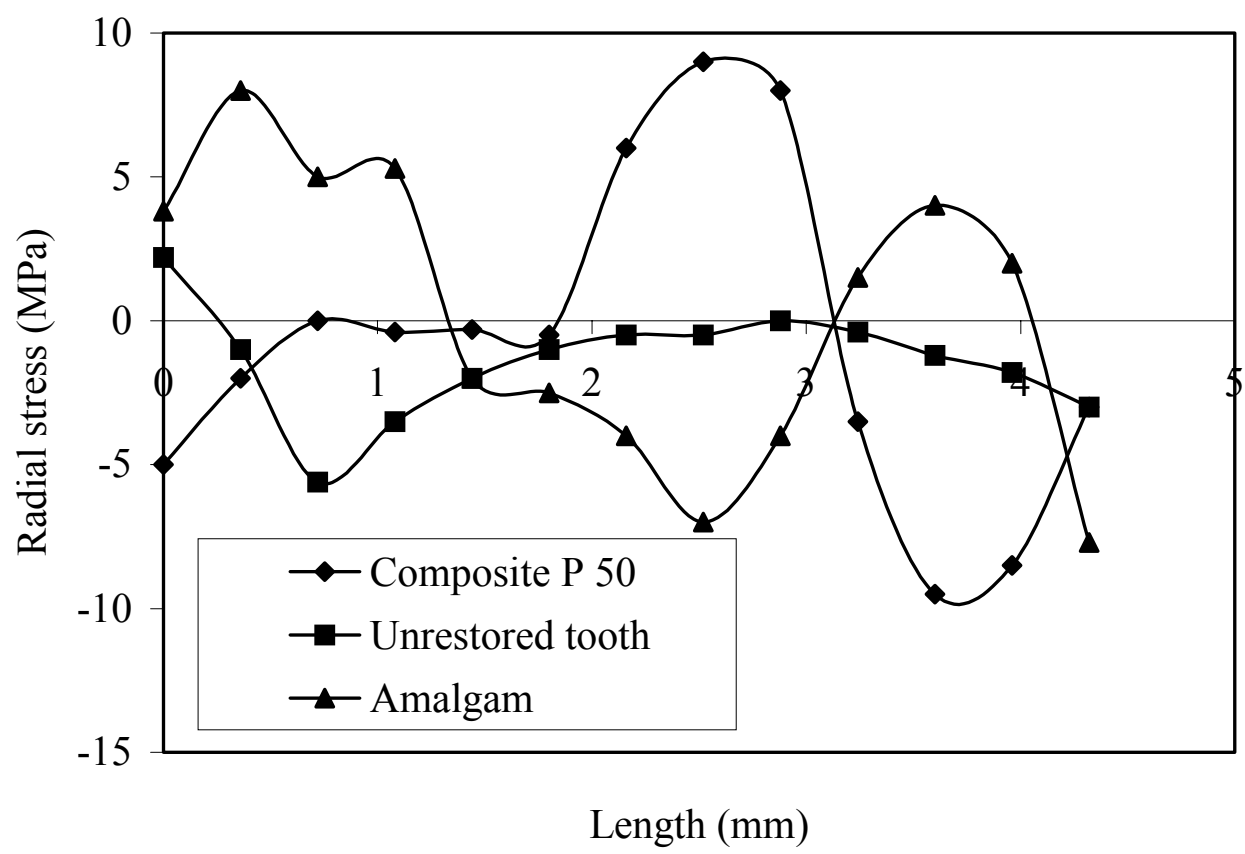

Fig. 6 The radial stress on glass inomer-restorative material interface

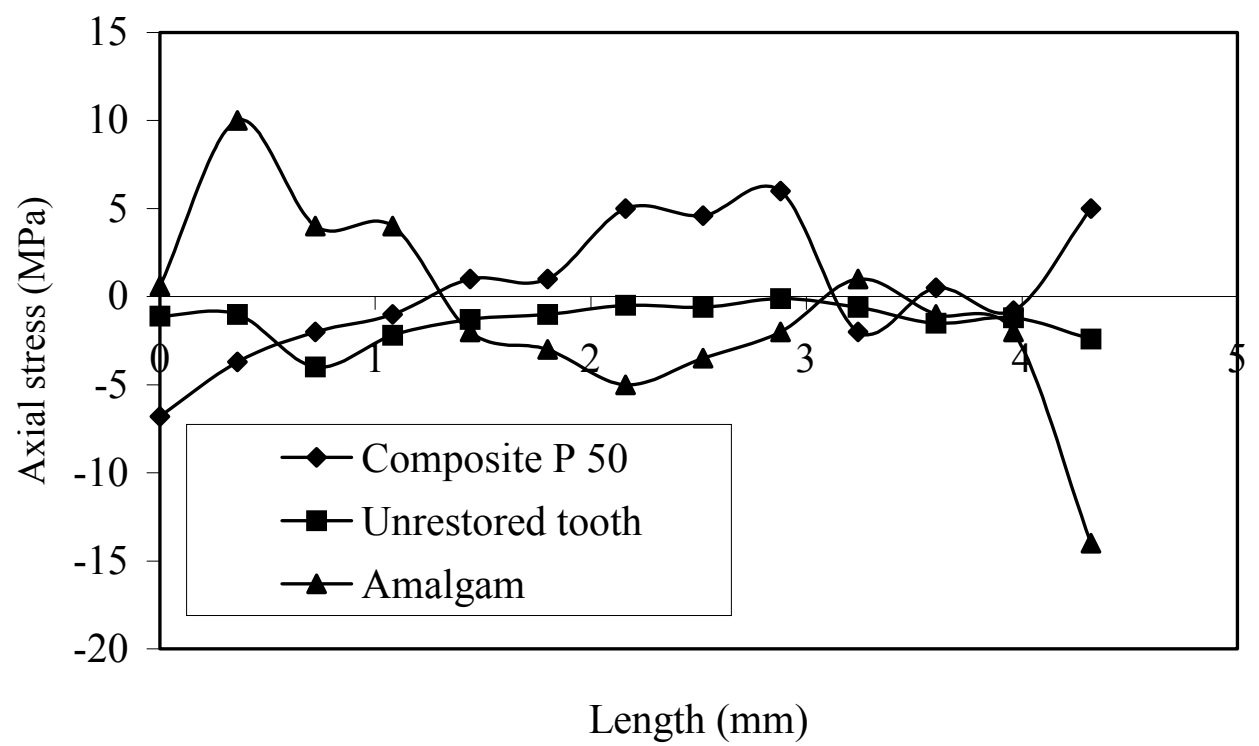

Fig. 7 The axial stress on glass inomer- restorative material interface 
On the restorative material, the radial, axial and shear stress distributions are almost the same tendency. As seen in Fig. 9, the variation of the stress values in the radial direction from the centre to $\mathrm{r}=2.5 \mathrm{~mm}$ are nearly zero. The maximum compressive stresses occur at $\mathrm{r}=4.3 \mathrm{~mm}$ when composite resin has been used. On the contrary, maximum tensile stress takes place when amalgam has been used as filler. The axial stress values are smaller than radial stress values.

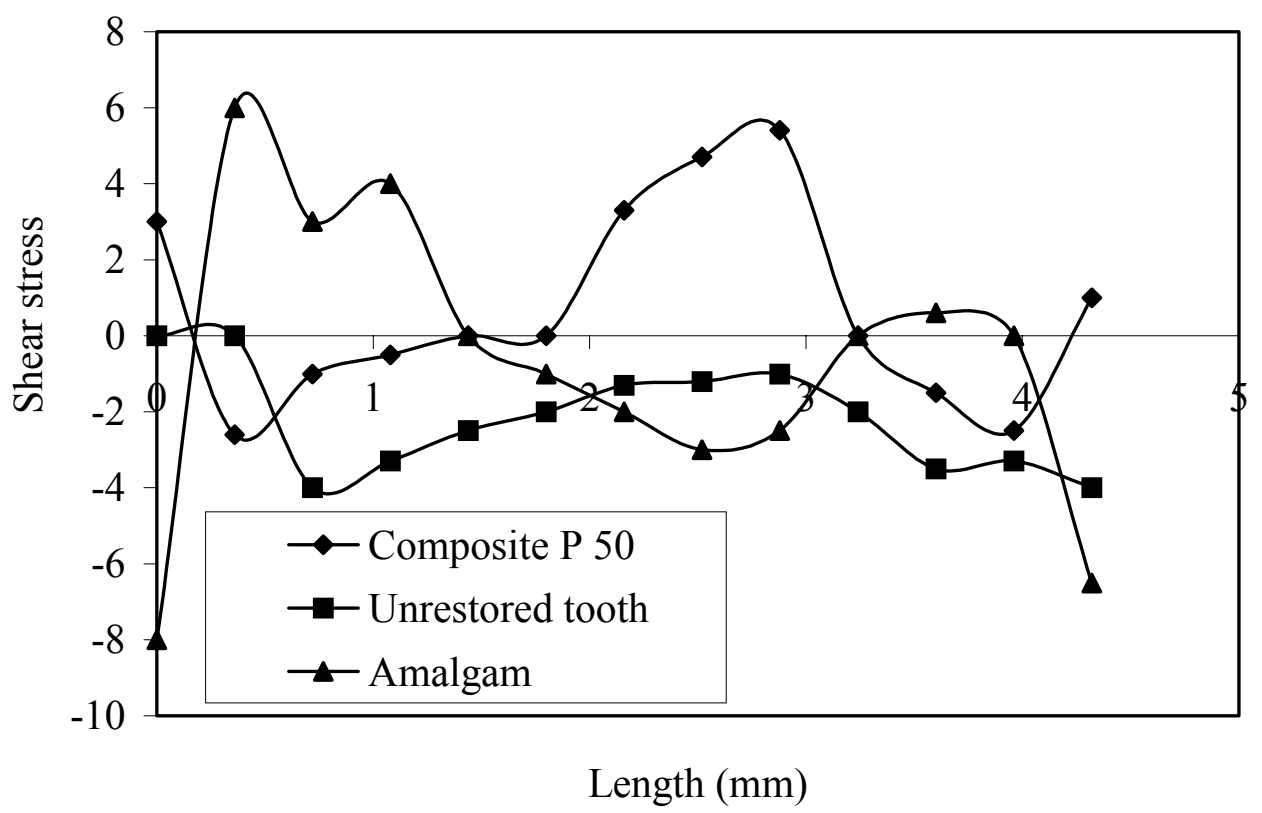

Fig. 8 The shear stress on glass inomer- restorative material interface

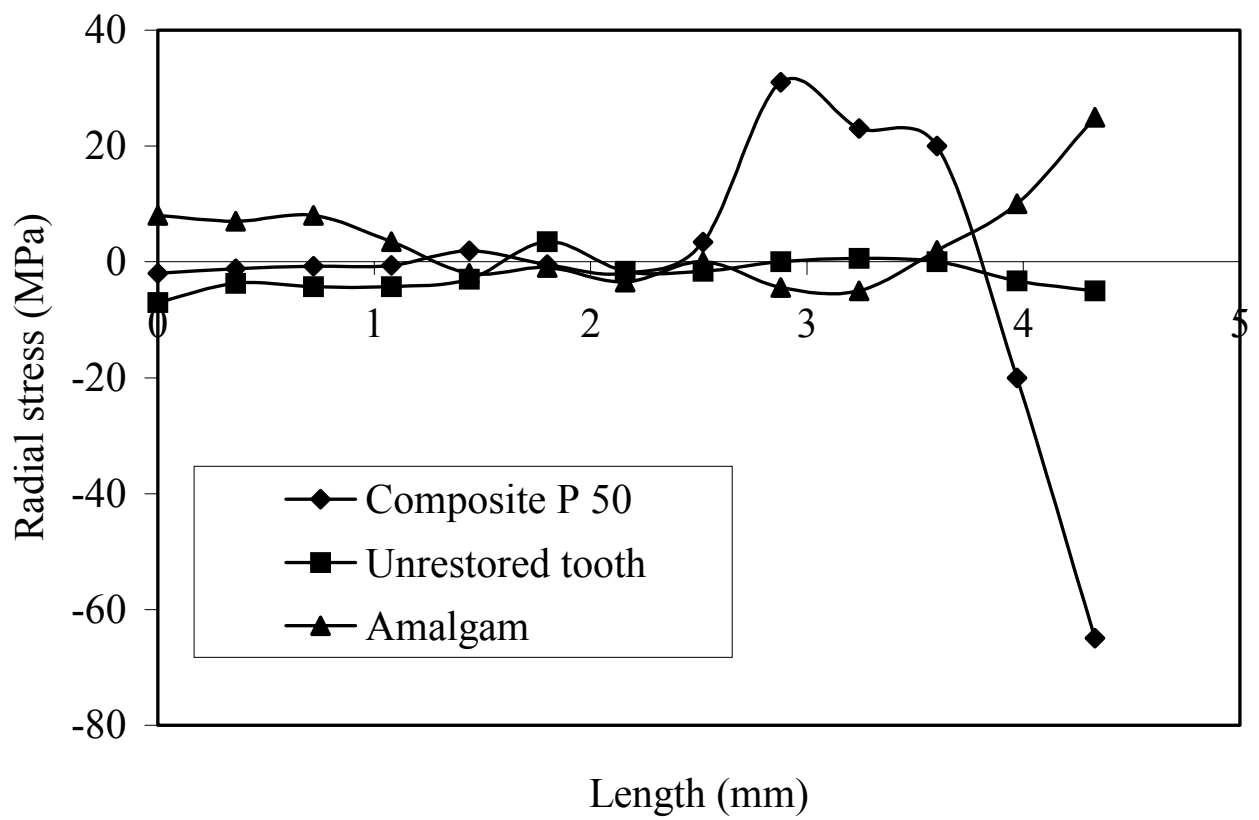

Fig. 9 The radial stress on restorative material 
The axial stress values on the restorative material are given Fig. 10. In case of composite resin the maximum compressive stress value reaches $32 \mathrm{MPa}$ on the surface of tooth, whereas when amalgam has been used the maximum tensile stress at on the centre of tooth is $16 \mathrm{MPa}$. In Fig. 11 the shear stress distribution in the restoration is given. The maximum tensile occur on the surface of tooth when composite resin has been used.

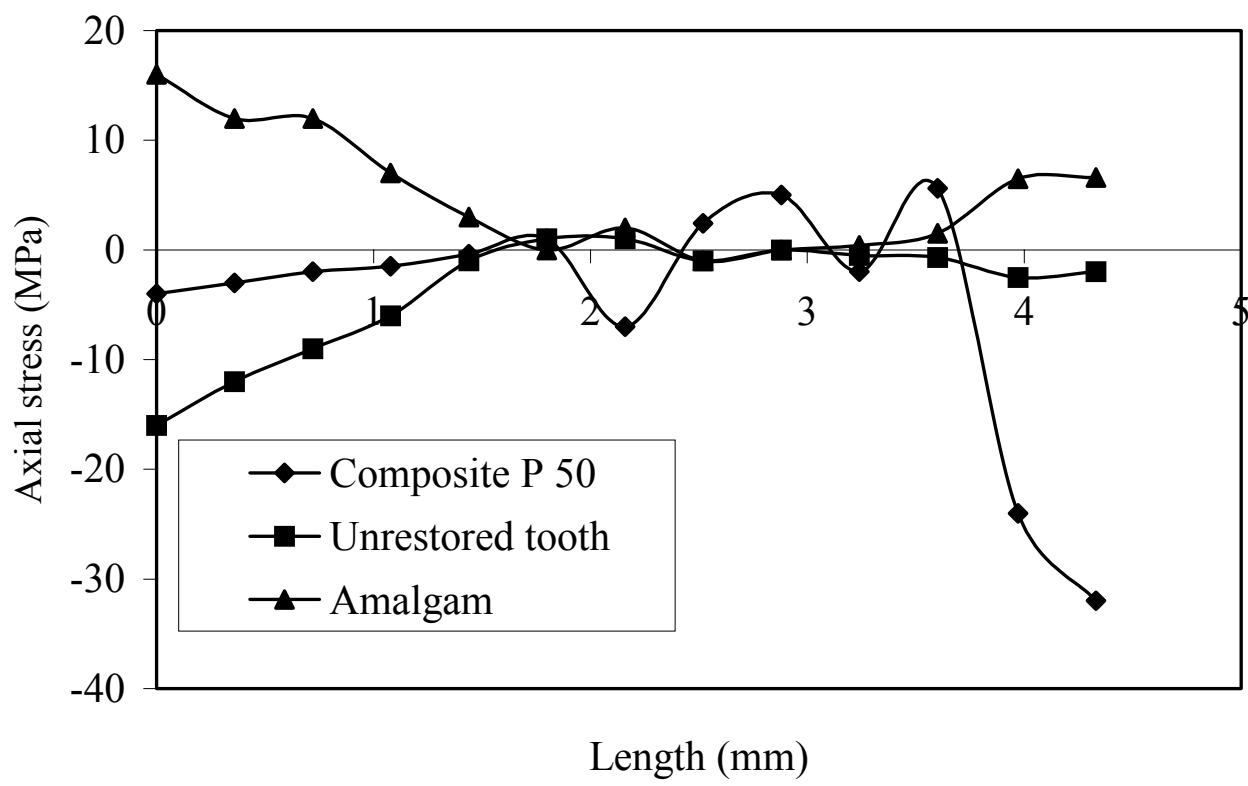

Fig. 10 The axial stress on restorative material

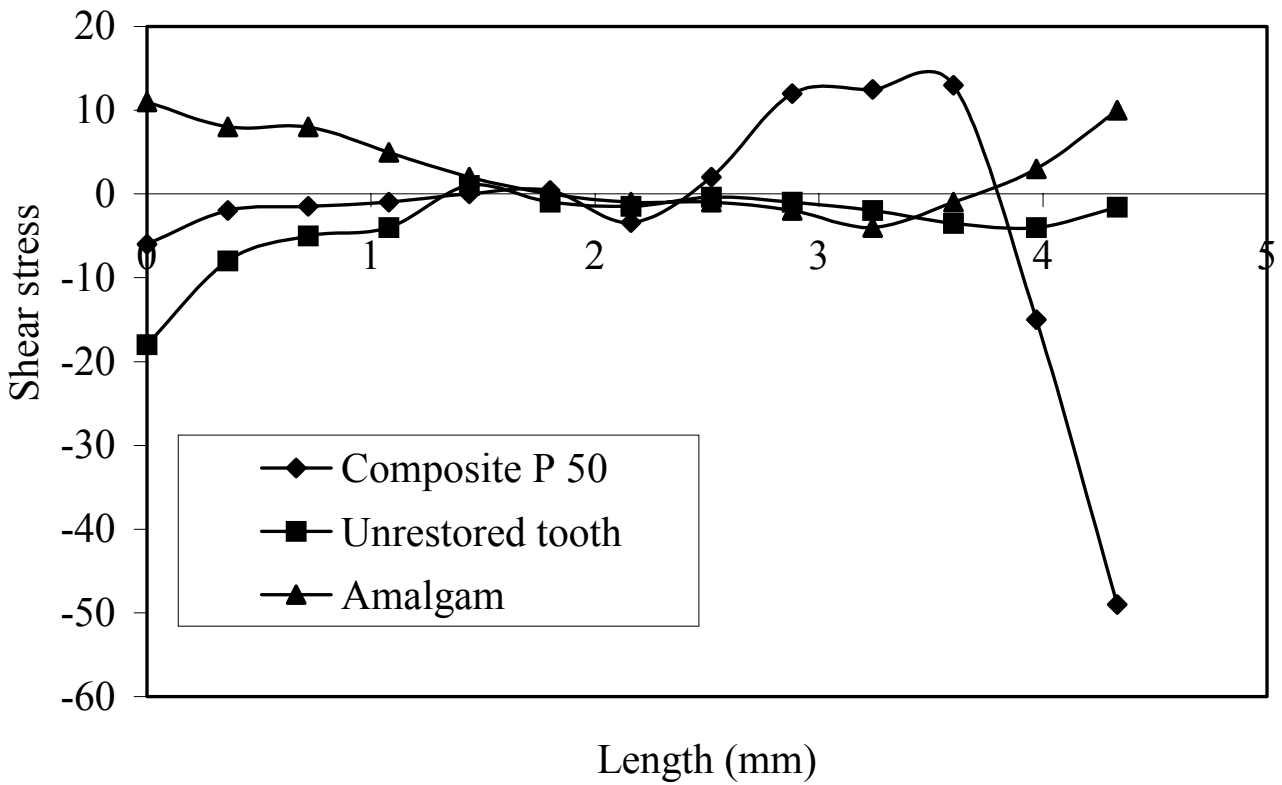

Fig. 11 The shear stress on restorative material 


\section{DISCUSSION}

A Finite element analysis of an unrestored a restored maxillary second premolar tooth with amalgam and composite resin was conducted. The effect of mechanical loading on the stress distribution within the interface and restoration were examined.

Finite element analysis is based on a continuum model in which the material is assumed to be continuous at all levels. Attempting to model an interface between two different materials is one of the most difficult tasks to accomplish with Finite element analysis. The essential problem is that the nodes that are common to the dentinrestoration interfaces will have two stress outputs relative to the materials forming the interface. Many commercial finite element programs overcome this problem by using an average nodal stress approach. The use of average nodal stresses to interpret interfacial phenomena is unrealistic, since the results are too heavily biased by the values of the materials modulus forming the interface. This problem was overcome by using specialized elements known as joint elements [11]. In this study, joint elements, which were usually used in engineering to model was used.

Previous finite element analysis has used three-dimensional models and a load of $1 \mathrm{~N}$ magnitude to study stress distributions within dentin [12] (Pao, Reinhardt \& Krejci, 1987). To represent a biologic entity more accurately, the present study used an axisymmetric, anatomically simulated model with $200 \mathrm{~N}$ forces delivered at $45^{\circ}$ angle to the long axis of the tooth. Toparli et al. [6] calculated stress distribution in a restored maxillary second premolar tooth, which occurred by the mastication force. This numerical study was carried out using three-dimensional finite element models. But these models did not include alveolar bone. However, in present study the axisymmetric finite element model with alveolar bone is selected.

\section{REFERENCES}

1. M.E. Gher, R.M. Dunlap, M.H. Anderson and L.V. Kuhl, Clinical survey of fractured teeth, Journal of the American Dental Association 114, 174-177, 1987.

2. W.S. Eakle, E.H. Maxwell and B.V. Braly, Fractures of posterior teeth in adults, Journal of the American Dental Association 112, 215-218, 1986.

3. R.B. Joynt, G. Weizkowski, R. Klockowski and E.L. Davis, Effects of composite restorations on resistance to cuspal fracture in posterior teeth, Journal of Prosthetic Dentistry 57, 431-435, 1987.

4. D.C. Reel and R.J. Mitchell, Fracture resistance of teeth restored with class II composite restorations, Journal of Prosthetic Dentistry 61, 177-180, 1989.

5. F.J.T. Burke, Tooth fracture in vivo and in vitro, Journal of Dentistry 20, 131-139, 1992.

6. M. Toparli, N. Gokay and T. Aksoy, Analysis of a restored maxillary second premolar tooth by using three-dimensional finite element method, Journal of Oral Rehabilitation 26, 157-164, 1999.

7. D. Arola, L.A. Galles and M.F. Sarubin, A comparison of the mechanical behavior of posterior teeth with amalgam and composite MOD restorations, Journal of Dentistry 29, 63-73, 2001. 
8. C.L. Lin, C.H. Chang and C.C Ko, Multifactorial analysis of an MOD restored human premolar using auto-mesh finite element approach, Journal of Oral Rehabilitation 28, 576- 2001.

9. M.M Ash, Wheeler's Atlas of Tooth Form, W.B. Saunders Company, Philadelphia, 1984.

10. M. Toparli and T. Aksoy, Fracture toughness determination of composite resin and dentin/composite resin adhesive interfaces by laboratory testing and finite elements models, Dental Materials 14, 287-293, 1998.

11. J.S. Rees and P.H. Jacobsen, The effect of cuspal flexure on a buccal Class V restoration: a finite element study, Journal of Dentistr, 26, 361-367, 1998.

12. Y.C. Pao, R.A. Reinhardt and R.F. Krejci, Root stress with tapered-end post design in periodontally compromised teeth, Journal of Prosthetic Dentistry 57, 281-287, 1987. 